ERJ

Engineering Research Journal

Faculty of Engineering

Minofia University

\title{
The Hydraulic and Environment Effect of El-Ain-Al Sokhna Power Plant
}

\author{
Yousra Khairy ${ }^{1}$ Esam Helal $^{2}$, Mohamed Sobeih ${ }^{3}$, Khaled Ramadan ${ }^{4}$
}

\author{
${ }^{1}$ Engineer, Hydraulics Research Institute ,National Water Research Center \\ ${ }^{2}$ Lecturer, Faculty of Engineering, Minofia University \\ ${ }^{3}$ Professor, Faculty of Engineering, Minofia University \\ ${ }^{4}$ Professor, Hydraulics Research Institute ,National Water Research Center
}

\begin{abstract}
The demand on electrical power in Egypt increase to supply industrial and public utility needs. In this manner new power plants are being constructed at different spots in Egypt in order to meet that demand. El-Ain-Al Sokhna super critical steam turbine $(2 * 650 \mathrm{MW})$ has been operated in 2012. It is located $52 \mathrm{Km}$ south Suez city The Power Plant uses a direct once through cooling system using water taken from the Suez Gulf and discharged with higher temperature. The discharge of processed water which has higher temperature affects both physical and chemical properties of water. It changes its density, vapour pressure, viscosity, surface tension, gas solubility, diffusion, and chemical reactions which have influence on the local physical, chemical and ecological of marine environment.

This paper studies the hydraulic and environment impact of the El-Ain-Al Sokhna power plant on the surrounding area under different wind conditions and tidal forces using numerical modeling. A hydrodynamic model for the study area has been developed using Delft3D. Data for site description, water levels, velocity measurements, wind data and water quality have been collected and used in model setup and calibration.

Different scenarios have been simulated under different tidal and wind conditions. The effect of changing the intake location and the feasibility of adding a breakwater to minimize the entrance of thermal plume from the El-Ain-Al Sokhna power plant and Suez Gulf power plant outfalls have been studied .The temperature distribution results have been compared with the environmental regulations Dimension analysis of the factors affecting the temperature distribution and an equation for the intake temperature have been developed.
\end{abstract}

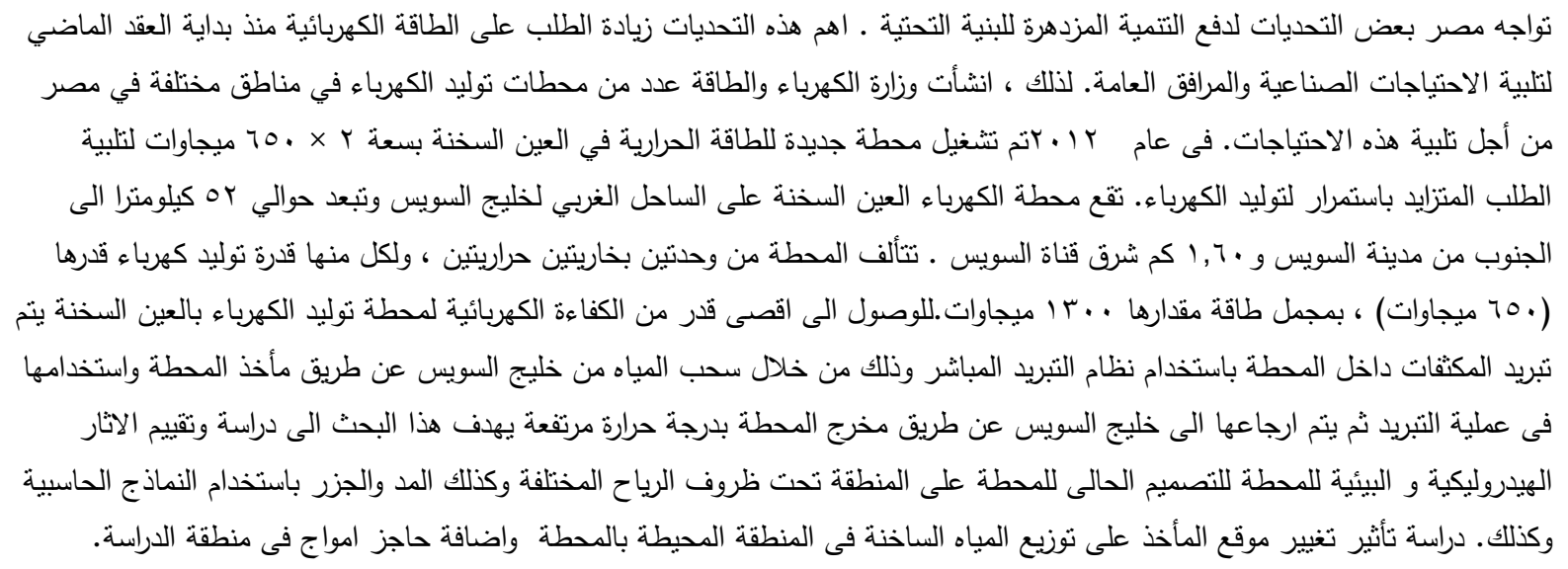

Key Words: Environmental, Power Plant, Intake, Breakwater 


\section{INTROUDUCTION}

Egypt, has some challenges to drive the booming development of infrastructure, and management of sustainable resources Ministry of Electricity and Energy has operated a new thermal power plant at El-Ain-Al Sokhna region to overcome the increase in power demand due to the expanding in tourism , resorts and industrial areas .El-Ain-Al Sokhna. (2x650 MW) super-critical steam power plant is located $52 \mathrm{~km}$ south of the city of Suez and 1.60 $\mathrm{km}$ east of the Suez/Red Sea Highway, which runs parallel to the Gulf of Suez.

Before constructing the El-Ain-Al Sokhna a study by the world bank was done to select the site and technology for the new plant from three locations . Different thermal power stations options were compared for location as well as plant design to determine optimal module size. Considerations in selecting the project site included the availability of fuel supply, cooling water for the plant, availability of sufficient land, and utilization of the existing transmission lines to evacuate power generated into the unified power generation system. World Bank 2009[1]

The El-Ain-Al Sokhna Power Plant incorporates a direct (once through) surface water cooling system using water taken from the Suez Gulf. The use of a direct cooling system maximizes the electrical efficiency of the power plant and, after use all the water will be returned back to the Gulf of Suez $8^{\circ} \mathrm{c}$ higher than the ambient temperature of the Suez Gulf water compared. The discharge of processed water which has higher temperature and salinity affects both physical and chemical properties of water. It changes its density, vapour pressure, viscosity, surface tension, gas solubility, diffusion, and chemical reactions which have influence on the local physical, chemical and ecological of marine environment. This paper studies the Hydraulic and Environment Effect of the power plant under different wind conditions and tidal forces using numerical modeling.

\section{LITERATURE REVIEW}

Literature was reviewed in the field of power plants and the cooling system and their effect on environment. From the reviewed literature, it was clear that Choosing the location of the cooling system in the water must be studied when planning for a new power plant. The data required for description of site in fresh or marine water locations were summarized by U.S. Environmental Protection Agency (1977)[2] as following :

1. Site location and : Location of additional intake structures and Smaller scale map showing locations of intake structures, associated cooling water systems, and other pertinent discharges related to surrounding shore and water features in a 50-mile radius.
2. Site Plan - Larger scale map with topographic and hydrographic data depicting specific location of structure in the water body.

3. Meteorology Data: Air temperature, maximum, minimum, and mean-monthly rainfall, Solar radiation, Wind speed and direction, prevailing winds identified as to seasonal patterns

4. Additional stresses on water body segment: Location of existing or planned point sources of potential adverse environmental impact

Baptist (2005) [3] has studied the effect of the cooling water discharges on living organisms as following:

- Thermal influence caused by a short-term or long-term exposure to high temperature in the discharge area

- Thermal damage caused by heating in the condenser

- Mechanical damage caused by the screens at the intake and by the flow through the cooling system (entrainment)

- Toxic damage caused by a detrimental water quality of cooling water.

\section{Data Collection}

To study the environmental impact of El-Ain-Al Sokhna power plant many information about the study area has to be known. Data was collected from different sources including research institutes, ministries and authorities which were used in establishing and calibrating the numerical model .

\subsection{Plant Description}

The El-Ain-Al Sokhna power plant $2 * 650 \mathrm{MW}$ has a once through cooling system using a discharge of $51 \mathrm{~m}^{3} / \mathrm{sec}$ with $8^{0} \mathrm{c}$ higher temperature. The intake of the power plant is $1000 \mathrm{~m}$ offshore pipeline system and the outfall is an onshore open channel Latif(2010) [4] .The plant is surrounded by Suez Gulf BOT power plant 2 x 241.25 MW using 26 $\mathrm{m}^{3} / \mathrm{sec}$ with $8^{0} \mathrm{c}$ higher temperature for it's once through cooling system.

Land boundaries and site geometry for El-Ain-Al Sokhna power plant and surrounding area was obtained from Google earth images as shown in Figure (1). 


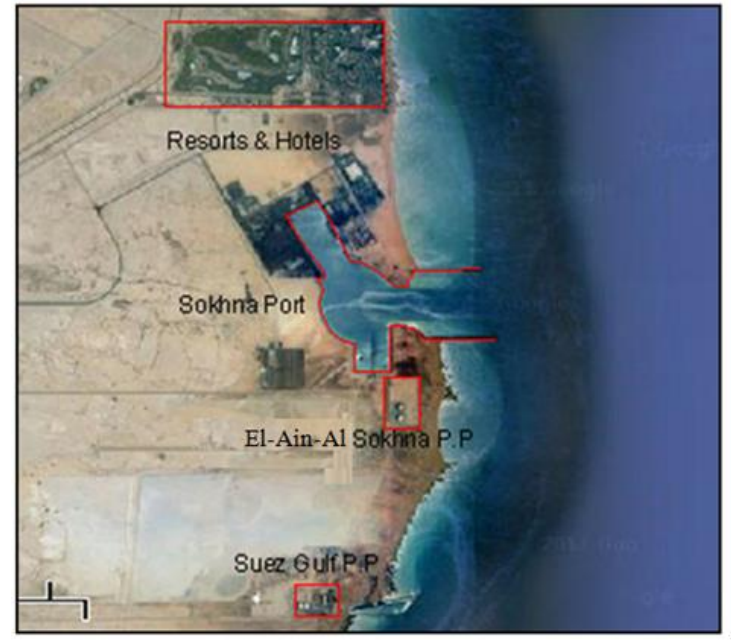

Figure (1) Location of El-Ain-Al Sokhna P.P.

\subsection{Survey Data}

Two field surveys were done by HRI. The first survey in 2008 covered an area of $36 \mathrm{Km}^{2}$, with a distance of $9.0 \mathrm{~km}$ along shore. The second survey was done in 2010 it was more detailed and covered $5 \mathrm{~km}^{2}$ on the vicinity of the El-Ain-Al Sokhna Power plant area with a distance of $2.5 \mathrm{~km}$ parallel to the shore line and $2.0 \mathrm{Km}$ normal to the shore. The survey has included bathymetric survey ,Topographic survey, measuring water level variations , current velocity and wind speed HRI (2009) [5].

\section{Numerical Model}

A hydrodynamic flow model for the study area was developed based on the collected data using Delft3D software to understand the changes in the El-Ain-Al Sokhna power plant surrounding area.

\subsection{Model Description}

Delft 3D flow module is basically a multidimensional (2D and 3D) hydrodynamic (and transport) simulation, which calculates unsteady flow, and transport phenomena on a curvilinear, boundary fitted grid. This module solves Navier Stokes Equations for an incompressible fluid, under the shallow water and the Boussinesq assumption. In the vertical direction, the vertical acceleration is neglected, which leads to the hydrostatic pressure equation. In 3D modeling, the vertical velocities are computed from the continuity equation. The set of partial differential equations in combination with an appropriate set of initial and boundary conditions is solved on a finite difference grid. In Delft3 intake stations and waste-water outfalls are considered as localized discharges of water and dissolved substances their locations are determined based on the computed wave, current velocity, and temperature patterns Delft3D-FLOW User Manual( 1999)[6].

The land boundary for the study area was obtained using Google images. A fine grid resolution with
$(10 \times 10 \mathrm{~m})$ grid size was produced at the area of interest $(3.0 \mathrm{~km}$ alongshore and $2 \mathrm{~km}$ offshore) to include the existing and the new power plant. A course grid resolution with $(40 \mathrm{x} 40 \mathrm{~m})$ grid size was formed for the remaining area which covers about $9.0 \mathrm{~km}$ alongshore and $4.0 \mathrm{~km}$ offshore HRI (2008)[7]. The model bathymetry was generated using the surveyed data.

The model simulation period was 35 days to cover two spring and neap cycle with time step 0.2 minute .The water density in the model was 1025 $\mathrm{Kg} / \mathrm{m}^{3}$ and the bed roughness manning coefficient was 0.081 .The sea ambient temperature was $26^{\circ} \mathrm{c}$ .Water level at 2 locations obtained from the admiliarty tables (HRI 2008) in the model corners was used as boundary conditions as tidal constituents at these stations.

\subsection{Model Calibration}

The model calibration is comparing the real field data with the numerical model results at two stations Table (1) presents the Local coordinates of the measurements locations (HRI2009). The modeled and observed water level and current velocity for a spring neap tidal cycle which represent the most seasonal variation is shown in Figures (2 to 5 ).

\begin{tabular}{|c|c|c|}
\hline Station No. & Easting & Northing \\
\hline Station 1 & 5763.6 & 8928.9 \\
\hline Station 2 & 6631.9 & 10589.6 \\
\hline
\end{tabular}

Table (1) Local coordinates of the measurements locations

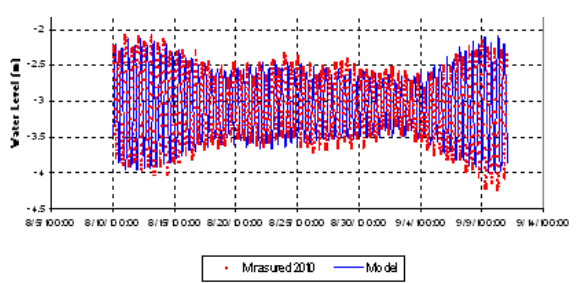

Figure (2) Computed and measured water levels for Station 1

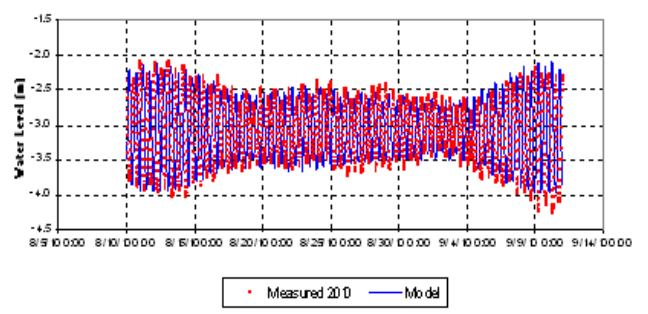

Figure (3) Computed and measured water levels for Station 2 


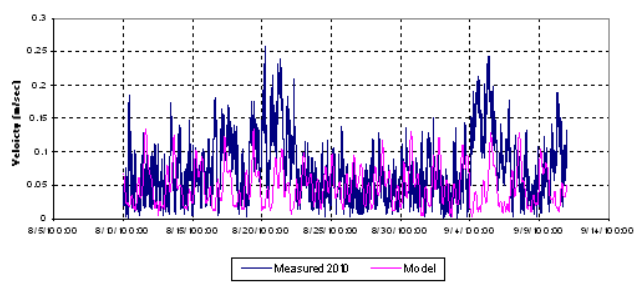

Figure (4) Computed and measured velocity for Station 1

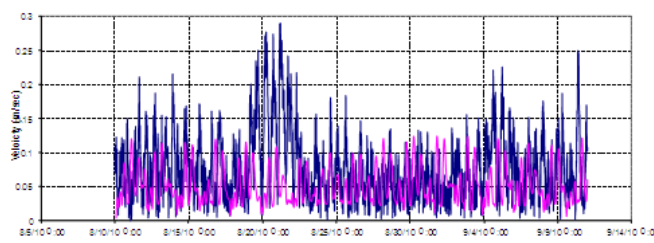

Figure (5) Computed and measured velocity levels for Station 2

From these Figures it is observed that the model results and observed water levels match in both magnitude and phase also it is observed that the tide at the study area is semi diurnal tide because the tidal cycle is repeated each 12 hours.

\subsection{Model Scenarios}

The objectives of the different Model Scenarios were

- Determining the major forces affecting the flow and hydraulic mixing.

- $\quad$ Studying the effect of changing the intake location in order to minimize the intake pipe cost.

- $\quad$ The feasibility of adding a breakwater to reduce the plume merge for El-Ain-Al Sokhna and Suez Gulf power plants

In order to achieve these objectives the scenarios were divided three groups. In each group several scenarios were simulated and the selected scenario is used as input for the second group. The hydraulic effect and the thermal discharge from the power were analyzed to study plume dispersion and recirculation at the plant site for a spring-neap tidal cycle in summer with an ambient temperature $26^{\circ} \mathrm{c}$.

Group (1) simulates the effect of operating the ElAin-Al Sokhna power plant under different wind and tidal conditions six scenarios were simulated. Scenarios AS01, AS03, and AS05 represent the area condition before constructing the new power for different wind and tidal conditions. Scenarios AS02, AS04 and AS06 represent the area condition after operating the new power plant for the same wind and tidal conditions. An overview of group (1) model scenarios is presented in Table (2).

\begin{tabular}{|c|c|c|c|c|c|}
\hline \multirow{2}{*}{ No } & \multirow{2}{*}{ Wind } & \multicolumn{2}{c|}{$\begin{array}{c}\text { Suez Gulf } \\
\text { P.P. }\end{array}$} & \multicolumn{2}{c|}{$\begin{array}{c}\text { El-Ain-Al } \\
\text { Sokhna P.P. }\end{array}$} \\
\cline { 3 - 6 } & & $\begin{array}{c}\text { Flow } \\
\mathrm{m} 3 / \mathrm{s}\end{array}$ & $\begin{array}{c}\Delta \mathrm{t} \\
{ }^{\circ} \mathrm{C}\end{array}$ & $\begin{array}{c}\text { Flow } \\
\mathrm{m} 3 / \mathrm{s}\end{array}$ & $\begin{array}{c}\Delta \mathrm{t} \\
{ }^{\circ} \mathrm{C}\end{array}$ \\
\hline AS 01 & No Wind & 26 & 8 & ---- & --- \\
\hline AS 02 & No Wind & 26 & 8 & 51 & 8 \\
\hline AS 03 & NE, 5m/s & 26 & 8 & ---- & --- \\
\hline AS 04 & NE, 5m/s & 26 & 8 & 51 & 8 \\
\hline AS 05 & $\begin{array}{c}\mathrm{NW}, \\
5 \mathrm{~m} / \mathrm{s}\end{array}$ & 26 & 8 & ---- & -- \\
\hline AS 06 & $\begin{array}{l}\mathrm{NW} \\
5 \mathrm{~m} / \mathrm{s}\end{array}$ & 26 & 8 & 51 & 8 \\
\hline
\end{tabular}

Table (2) Group (1) scenarios

Group (2) Scenarios studies changing the configuration of the cooling intake structure which is defined as the total structure used to direct water into the component of cooling system .The major portion of water is directed to absorb the waste heat rejected .In group (2) seven scenarios (AS07 to AS13) were simulated with different pipe line lengths as presented in Table (3) .

\begin{tabular}{|c|c|c|c|c|}
\hline \multirow{2}{*}{ No } & \multirow{2}{*}{ Wind } & \multicolumn{3}{|c|}{ El-Ain-Al Sokhna P.P. } \\
\cline { 3 - 5 } & & $\begin{array}{c}\text { Flow } \\
\mathbf{m}^{\mathbf{3}} / \mathbf{s}\end{array}$ & $\begin{array}{c}\Delta \mathbf{t} \\
{ }^{\circ} \mathbf{C}\end{array}$ & $\begin{array}{c}\text { Intake } \\
\text { Location }\end{array}$ \\
\hline AS07 & No Wind & 51 & 8 & $350 \mathrm{~m}$ offshore \\
\hline AS08 & No Wind & 51 & 8 & $500 \mathrm{~m}$ offshore \\
\hline AS09 & No Wind & 51 & 8 & $800 \mathrm{~m}$ offshore \\
\hline AS10 & No Wind & 51 & 8 & $850 \mathrm{~m}$ offshore \\
\hline AS11 & No Wind & 51 & 8 & $900 \mathrm{~m}$ offshore \\
\hline AS12 & No Wind & 51 & 8 & $950 \mathrm{~m}$ offshore \\
\hline AS13 & No Wind & 51 & 8 & $\begin{array}{c}1250 \mathrm{~m} \\
\text { offshore }\end{array}$ \\
\hline
\end{tabular}

Table (3) Group (2) scenarios.

Group (3) simulates the feasibility of adding a breakwater to reduce the plume merge for El-AinAl Sokhna and Suez Gulf power plants by changing configuration is changing the intake structure to be surrounded by a breakwater which makes a barrier decreasing the plume from the outfall so the water taken by the intake is with less temperature. Three scenarios were simulated with different breakwater length to select the optimum solution. Table (4) summarizes Group (3) scenarios. 


\begin{tabular}{|c|c|c|c|c|}
\hline \multirow{2}{*}{ No } & \multirow{2}{*}{ Wind } & \multicolumn{3}{|c|}{ El-Ain-Al Sokhna P.P. } \\
\cline { 3 - 5 } & & $\begin{array}{c}\text { Flow } \\
\mathbf{m 3 / s}\end{array}$ & $\begin{array}{c}\Delta \mathbf{t} \\
{ }^{\circ} \mathbf{C}\end{array}$ & $\begin{array}{c}\text { Breakwater } \\
\text { Length }\end{array}$ \\
\hline AS14 & No Wind & 51 & 8 & $350 \mathrm{~m}$ offshore \\
\hline AS15 & No Wind & 51 & 8 & $500 \mathrm{~m}$ offshore \\
\hline AS16 & No Wind & 51 & 8 & $\begin{array}{c}1000 \mathrm{~m} \\
\text { offshore }\end{array}$ \\
\hline
\end{tabular}

Table (4) Group (3) scenarios

\section{Dimension Analysis}

The dimensional analysis is a mathematical method used in solving engineering problems involving fluid dynamics and thermodynamic where different variables are considered affecting the phenomenon.

The dimensional analysis was used to relate the different dependent and independent variables .The various variables that affect temperature to know the optimum pipe length at El-Ain-Al Sokhna intake are shown in Figure (6).

- $\mathrm{T}_{\mathrm{in}}$ : Temperature at intake

- $\mathrm{T}_{\mathrm{a}}$ :Ambient Temperature

- D : Distance between the two plants

- $\mathrm{L}_{\mathrm{i}}$ : Sokna P.P. intake pipe length

- $\mathrm{Y}_{\mathrm{i}}:$ : Water depth at the intake point

- $\mathrm{H}_{\mathrm{i}}$ : Water Level at the intake point

- $\mathrm{S}_{1}$ : Distance between the intake and outfall of Sokhna P.P.

- $\mathrm{S}_{2}$ : Distance between the intake and outfall of Suez Gulf P.P.

- Wp: The thermal plume width at $27 \mathrm{c}$

- Lp: The thermal plume Length at $27 \mathrm{c}$

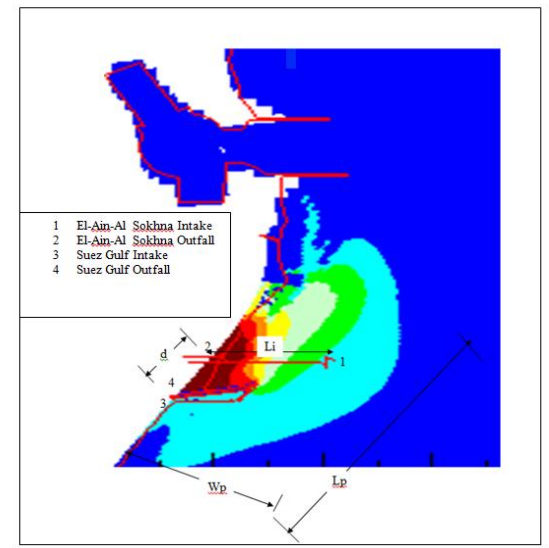

Figure (6)Layout of the intake pipe

The equation developed to calculate the intake temperature for the study area is

$$
\frac{T_{i n}}{T_{a}}=f\left(\frac{L_{i}}{Y_{i}}, \frac{H_{i}}{D}, \frac{S_{1}}{S_{2}}, \frac{W_{p}}{L_{p}}\right)
$$

\section{Model Results}

The temperature distribution before and after constructing El-Ain-Al Sokhna Power Plant with no wind condition scenarios AS01 and ASO2 are shown in Figure (7). The results of the model shows that the plume spread in the flood case is bigger than in the ebb case it has entered the Sokhna port with increase less than $0.5^{\circ} \mathrm{c}$ The rise in temperature above the ambient seawater in the plants vicinity didn't exceed the environmental regulations.

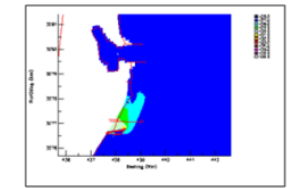

ASO1 Before El-Ain-AI Sokhna P.P Flood Flow
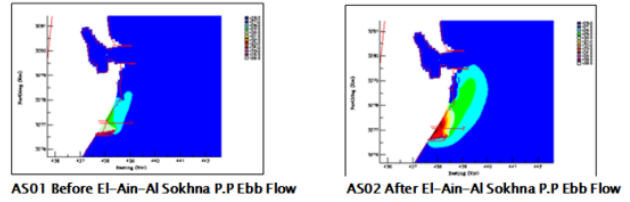

Figure (7) Temperature distribution for No Wind condition for Ebb and Flood flow

The results of scenarios AS03 to AS06 show the temperature distribution for NW and NE conditions in flood case as shown in Figure (8). The results show that the best recirculation is the NW wind condition and no wind condition gives the worst recirculation results. But in all cases the rise in temperature doesn't exceed the permissible environmental regulations.
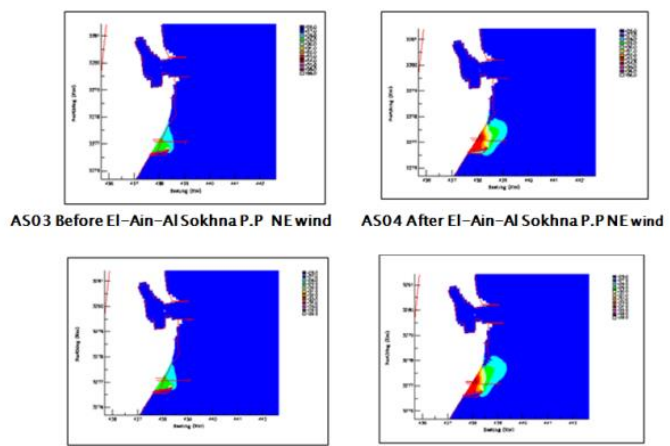

AS05 Before El-Ain-Al Sokhna P.P NW wind AS06 After El-Ain-Al Sokhna P.P NW wind

Figure (8) Temperature distribution for different wind conditions

Changing the intake location by decreasing the pipe length has resulted in different temperatures in front of the intake as shown in Figure (9). From the results it can be observed that we can't decrease the pipe length than $850 \mathrm{~m}$ offshore because the 
increase in the temperature is more than $1^{\circ} \mathrm{c}$ in the flood flow in the no wind case .

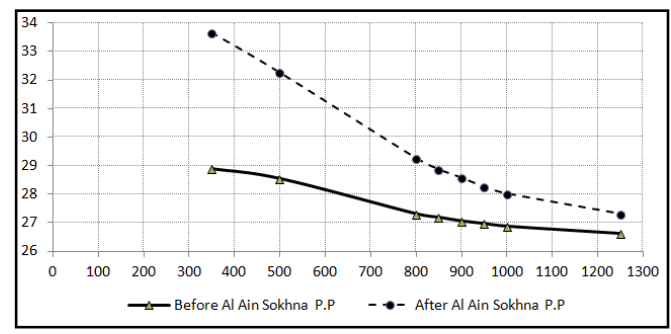

Figure (9) The Temperature at El-Ain-Al Sokhna Intake for different pipe lengths

Using the results of group (2) scenarios and solving the equation (1) the values of the variables effecting the flow was solved using 175 records 150 records was used in solving the equation and 25 record were used in the validation .The standard error was $93 \%$.The validation results is shown in Figure (10).The final equation (2) for the intake temperature is

$$
\frac{T_{i}}{T_{a}}=0.155 \frac{L_{i}}{L_{p}}+0.021 \frac{H_{i}}{Y}-0.086 \frac{D}{W_{p}}-0.1477 \frac{S_{1}}{S_{2}}+1.317
$$

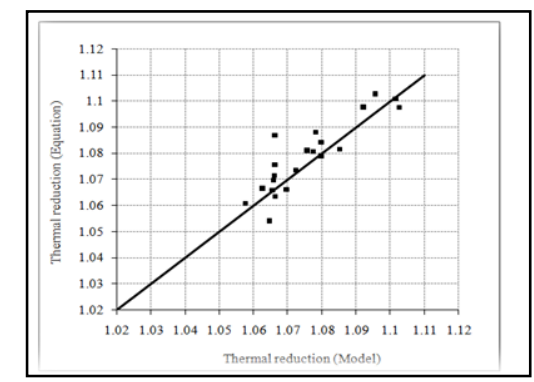

Figure (10) Equation validation results

Adding a breakwater in the intake location in group (3) scenarios has changed the temperature distribution in around the El-Ain-Al Sokhna power plant .The temperature distribution for scenario AS15 with breakwater length $500 \mathrm{~m}$ is shown in Figure (11).

Comparing the results of scenarioAS02 with scenario AS15 it can be indicated that the plume has been separated for $500 \mathrm{~m}$ offshore but the plume width has been increased.

The temperature distribution for scenario and AS16 with breakwater length $1 \mathrm{~km}$ is shown in Figure (12) .from the results it can be indicated that the plume has been separated for a larger distance but the width of the plume has been increased to cover the whole port entrance.

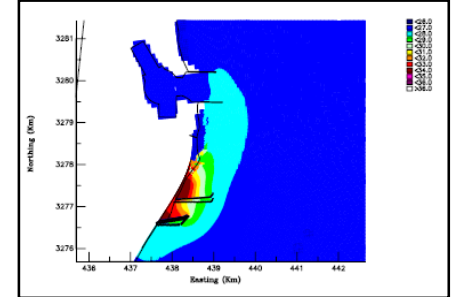

Figure (11) Temperature distribution forBW500 m case of ebb flow

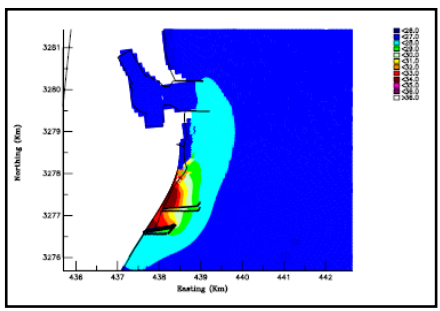

Figure (12) Temperature distribution for BW $1 \mathrm{~km}$ case of ebb flow

The temperatures in front of El Ain Al Sokhna and Suez Gulf intakes have changed with different breakwater length. The temperature as shown in Figures (13) and (14). Comparing the temperature at each scenario at El-Ain-Al Sokhna intake we can conclude that breakwater length $350 \mathrm{~m}$ and $500 \mathrm{~m}$ have the same temperature $\left(29^{\circ} \mathrm{c}\right)$ in front of the intake but that the temperature have been decreased by $1.5^{\circ} \mathrm{c}$ in the case of breakwater length $1 \mathrm{~km}$. The temperature for Suez Gulf intake is constant for different breakwater lengths.

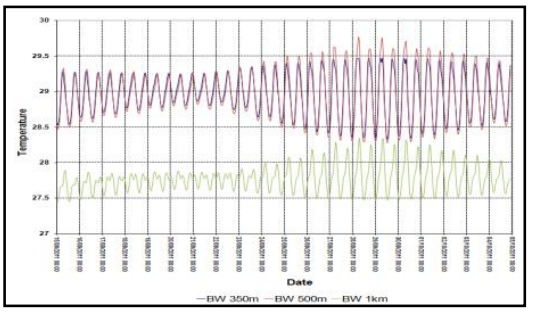

Figure (13) Temperature of El-Ain-Al Sokhna Intake for different breakwaters

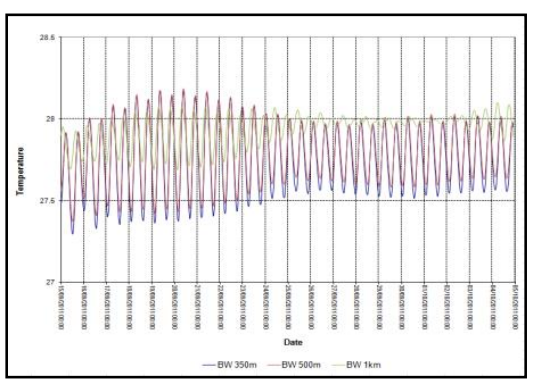

Figure (14) Temperature of Suez Gulf Intake for different breakwaters 


\section{Conclusions \& Recommendations}

- Before constructing a new power plant, the environmental effect on the surrounding area and its influence on the surrounding power plants have to be studied.

- The critical wind condition is the no wind case which gives poor mixing, resulting in the highest temperature in the mixing zone .

- The temperature distribution is affected with the changes in water levels due to tidal variation in the spring and neap cycles.

- Adding the breakwater which acts as a barrier separating the plume merge between the two power plants has decreased the temperature by less than $10 \mathrm{C}$, which is costly from the economic point of view.

- The intake pipe length can be decreased to $850 \mathrm{~m}$ where the rise in temperature after operating the new power plant is less than 10C which decreases the cost of the intake configuration.

- An equation for the temperature at the intake location was developed using the different parameters affecting the flow and temperature.

$\frac{T_{i}}{T_{a}}=0.155 \frac{L_{i}}{L_{p}}+0.021 \frac{H_{i}}{Y}-0.086 \frac{D}{W_{p}}-0.1477 \frac{S_{1}}{S_{2}}+1.317$

\section{References}

1. World Bank (2009), Egypt. "Ain Sokhna thermal power project" Appraisal Document, World Bank .

2. U.S. Environmental Protection Agency (1977) , "Guidance for evaluating the adverse impact of cooling water intake structures on the aquatic environment", Section ,316(b) P.L. 92-500.

3. M.J. Baptist and W.S.J. Uijttewaal (2005), "Transport and mixing of cooling water guidelines and modelling practice " , Ministry of Transport Public Works and Water Management, RwsRiza, project number WIA/1377

4. Latif ,Kotb (2010)," Investigating the environmental Impact of power plant Intakes and outfalls under tidal influence (case study :Suez Gulf -Egypt)",Nile basin water science and engineering journal, Vol 3, 52-63.

5. Hydraulics Research Institute (2009)," "Extension Measurements at Al-Ain-Al Sokhna power plant " HRI ,Report no $81 / 2009$

6. Hydraulics Research Institute (2008)," Hydrothermal modeling of the cooling system of the new power plant at El-Ain Al-Sokhna, Gulf of Suez, Red Sea(Two New Steam Units with a Capacity of $2 \mathrm{x}$ $650 \mathrm{MW}) "$ HRI, Report no 171/2008.

7. Delft3D flow Manual (2011) "Simulation of multi-dimensional hydrodynamic and transport phenomena, including sediments", User Manual, Hydro-Morphodynamics. 